\title{
Think Twice before Typing: Does Recall Message Strategy Affect Firm Valuation? An Abstract
}

\author{
Fatma Hilal Ergen Keles, Burc Ulengin, and Emrah Keles
}

\begin{abstract}
Product recalls are increasing worldwide. According to recent Reuters news, US automobile recalls hit record in 2016 with 53.2 million recalled products. This increase is attributed to several reasons such as increased product complexity, high product quality and safety expectation, global production, and closer monitoring by companies and government agencies. The results of product recalls influence firms depending on the recall reason(s) and the consequences they cause. Despite product recall management and communication during a product harm crisis could be very decisive, communication and marketing strategies are still under examined areas of the crisis management context. Especially when this increase is considered, managing recalls gains more and more importance. Harm crisis can damage firm reputation, decrease the interest of investors and customers which could affect the returns in a negative way, etc. Besides these deficiencies, firms are confronted with remedy costs which could reach high amounts. An optimum communication strategy could be a less costly strategy in harm crisis communication and managing processes to help firms to minimize the negative effects and costs for the firm. The main aim of this study is to provide understanding of how a company can minimize the negative effect of a product recall on financial value by benefiting from recall message characteristics. Studies concerning with minimizing the negative effect of product recalls by applying marketing strategy are rare. Therewithal to best of our knowledge, the recall message content's impact on financial value in the product recall context has not been investigated. This study aims to contribute to the literature by examining this gap.
\end{abstract}

References Available Upon Request

\author{
F. H. E. Keles $(\varangle) \cdot$ B. Ulengin \\ Istanbul Technical University, Istanbul, Turkey \\ e-mail: hilal.ergen@itu.edu.tr; ulenginbur@itu.edu.tr \\ E. Keles \\ Marmara University, Istanbul, Turkey \\ e-mail: emrah.keles@marmara.edu.tr
}

(C) Academy of Marketing Science 2019 